\title{
Evaluación médico-legal del abuso sexual infantil. Revisión y actualización
}

\section{Medico-legal evaluation of sexual abuse in children. Review and update}

\section{Resumen}

El diagnóstico de abuso sexual de niñas y niños casi siempre es un difícil desafío para el médico forense. En la mayoría de los casos el agresor es un familiar o una persona muy allegada y, en las edades más tempranas, casi nunca existe penetración anal o vaginal. Estas características determinan que los hallazgos periciales difieran complemente de los que se encuentran en las víctimas adultas de agresiones sexuales. Es necesario conocer la sensibilidad y especificidad de los hallazgos capaces de asociarse con abuso sexual, y la manera de evitar pasar por alto los casos reales o formular diagnósticos erróneos, ya que ambas situaciones generan un considerable daño a las niñas, niños y sus familias. Especialmente se debe relativizar la importancia de un examen genital y anal negativo, a la vez que se debe ser prudente al atribuir al abuso sexual los hallazgos anormales genitales o anales. Se jerarquiza el valor de la entrevista a la presunta víctima y la necesidad de que se lleve a cabo bajo estándares mínimos. En esta puesta al día se discute el valor diagnóstico de los signos y síntomas atribuibles a abuso sexual y se concluye con la formulación de diez reglas de aplicación general para el trabajo médico-legal en la materia.

Palabras clave: Abuso sexual infantil. Evaluación de hallazgos ano-genitales. Evaluación del himen. Informe pericial.

\section{Abstract}

Diagnosing child sexual abuse is usually a hard challenge for Forensic Doctors. In most cases, the sex offender is a relative or somebody who is really close to the victim, and at early ages there is seldom any anal or vaginal intercourse. As a result, findings in these cases are completely different from the once found in adult victims who suffered from sexual attacks. We need to learn about the sensitivity and specificity of findings that may be associated with child sexual abuse, in order to avoid ignoring real cases or perform mistaken diagnosis, since both situations cause significant harm to the boy, the girl and their families. We specially need to understand the low importance of a negative anal/genital exam and, at the same time, consider we face a case of abuse whenever abnormal anal or genital findings are present. We emphasize on the value of interviewing the alleged victim, and the need for it to be carried out according to minimum standards. The present article comprises the diagnostic value of child sexual abuse signs and symptoms and as a conclusion suggests ten rules to be generally applied in medico-legal work in the field.

Key words: Child sexual abuse. Evaluation of ano-genital findings. Hymen evaluation. Expert opinion.

\section{Introducción}

Según la definición adoptada por la Organización Mundial de la Salud, el abuso sexual de niñas y niños "consiste en la participación de un niño en una actividad sexual que no comprende plenamente, a la que no es capaz de dar un consentimiento, o para la que por su desarrollo no está preparado y no puede expresar su consentimiento, o bien que infringe las leyes o los tabúes sociales. El abuso sexual de menores se produce cuando esta actividad tiene lugar entre un niño y un adulto, o bien entre un niño y otro niño o adolescente que por su edad o desarrollo tiene con él una relación de responsabilidad, confianza o poder. La actividad tiene como finalidad la satisfacción de las necesidades de la otra persona" ${ }^{1}$.

\section{H. Rodríguez-Almada}

Doctor en Medicina. Especialista en Medicina Legal. Profesor Agregado de Medicina Legal de la Facultad de Medicina de la universidad de la República (Uruguay) Director Adjunto del Master a Distancia en Medicina Forense de la Universidad de Valencia (España).

Correspondencia: Dr. Hugo Rodríguez Almada E-mail: hrodriguez@fmed.edu.uy

Fecha de recepción: 15.MAR.2010

Fecha de aceptación: 15.MAR.2010 
En algunas legislaciones, el abuso sexual constituye un tipo penal independiente (caso de España), mientras que en otras se encuentra subsumido en otros tipos, como el de violación o atentado violento al pudor (caso de Uruguay).

En todo caso, el diagnóstico médico-forense de abuso sexual de niñas y niños generalmente constituye un difícil desafío. Las consecuencias de un error pericial en la materia son tan graves cuando se pasa alto el abuso sexual como cuando se realiza su diagnóstico erróneo².

El abuso sexual presenta características distintivas que, a los efectos del trabajo pericial, lo diferencian nítidamente de los atentados sexuales sobre personas adultas, a saber:

- La mayoría de los casos de abuso sexual son intradomiciliarios o perpetrados por personas muy allegadas y alrededor de un tercio son de carácter incestuoso.

- La mayoría de los casos de abuso sexual no incluyen una verdadera penetración vaginal o anal ${ }^{2-7}$.

Estas dos características son determinantes de los hallazgos clínicos (anamnesis y examen físico) y paraclínicos que podrá encontrar el médico forense para fundar su diagnóstico. Además, explican las sustanciales diferencias periciales que existen entre los atentados sexuales con víctimas adultas o infantiles.

El presente artículo es una puesta al día sobre la tarea pericial en los casos de presunto abuso sexual de niñas o niños.

\section{Posibles patrones periciales}

Los posibles hallazgos periciales en un niño o niña sexualmente abusados son extraordinariamente variables: desde verdaderas destrucciones del aparato genital hasta la completa ausencia de signos objetivables.

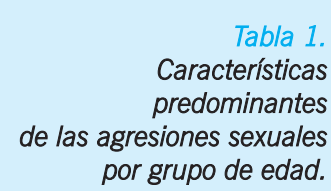

\begin{tabular}{lcc}
\hline & Adultos & Niños \\
\hline Lugar de ocurrencia & Extra-domiciliario & Intradomiciliario \\
\hline Denuncia de la víctima & Frecuente & Rara \\
\hline Signos genitales & Frecuentes & Raros \\
\hline Signos anales & Frecuentes & Raros \\
\hline Signos de violencia extra-genital & Frecuentes & Excepcionales \\
\hline Signos de violencia en el agresor & Posibles & Excepcionales \\
\hline
\end{tabular}

Más de allá de su variabilidad, es posible establecer dos grandes patrones de presentación bien definidos, que están en función del crecimiento y el desarrollo de los niños.

En las/os niñas/os menores de 6 años presentan un patrón completamente diferente que en las personas adultas. Mientras tanto, en escolares mayores y adolescentes pueden presentarse situaciones intermedias. Este límite de los 6 años -algo arbitrario, pero de utilidad práctica-, establece la edad por debajo de la cual, según Gisbert Calabuig, "el coito es anatómicamente imposible" en las niñas ${ }^{8}$.

Mientras que en los adolescentes son de aplicación los principios médico-legales clásicos empleados para la peritación de los atentados sexuales, en los niños -sobre todo, cuanto más pequeños son-, estos criterios carecen por completo de utilidad y acarrean el enorme riesgo de hacer pasar desapercibido el abuso sexual.

La Tabla 1 esquematiza las principales de estas diferencias.

De la tabla surge que, en las víctimas adultas el diagnóstico se basa fundamentalmente en la denuncia y en los signos de violencia genital, anal y/o extra-genital, todo lo que es muy raro encontrar en los abusos infantiles.

\section{Signos y síntomas de abuso sexual}

Los síntomas y signos de abuso sexual en niñas y niños pueden dividirse según su sensibilidad y especificidad. Precisamente, el patrón pericial general del abuso sexual en los niños y niñas se caracteriza por la presencia casi constante (por ello, muy sensibles) de algunos signos de muy escasa especificidad, por ello poco confiables, ya que pueden encontrarse en ausencia de abuso sexual2,3,5,7,9. Allí estriba el principal desafío pericial del abuso sexual, ya que obliga al perito a desarrollar un alto índice de sospecha, que debe unir a un gran sentido de la prudencia en la interpretación técnica y objetiva de los hallazgos.

\section{Elementos con alta especificidad diagnóstica}

En la práctica médico-legal es muy raro encontrar signos específicos que permitan hacer diagnóstico de abuso sexual en una niña o un niño. Ello tiene que ver con las formas más frecuentemente adoptadas por el abuso: intradomiciliaria, perpetrado por alguien conocido, que se estimula sexualmente sin que exista una verdadera penetración del pene. 
No obstante, en ocasiones se encuentran elementos de alta especificidad que permiten por si mismos hacer el diagnóstico o acercarlo sustancialmente.

\section{Gravidez}

Es el más específico de los signos, pero es de presentación muy poco frecuente. La constatación de un embarazo de una niña por debajo de la edad que las leyes de su país establecen como la mínima para consentir el coito, es una forma de objetivar un abuso sexual ${ }^{2,7}$.

\section{Infecciones de transmisión sexual (ITS)}

Las ITS son enfermedades capaces de transmitirse por contagio sexual. Sin embargo, muchas de ellas presentan otras formas de contagio, por lo que su especificidad como signo de abuso sexual es muy variable y no basta con el diagnóstico etiológico, sino que debe intentar establecerse la forma de contagio en el caso en estudio ${ }^{9,10}$.

Hemos esquematizado la especificidad de la ITS en tres grandes grupos ${ }^{7}$ :

- Grupo $1(+++)$. Muy alta especificidad. Su diagnóstico en un niño o niña, una vez descartada la infección connatal, establece diagnóstico de abuso sexual hasta demostración de lo contrario: sífilis, gonorrea y Chlamydia trachomatis.
- Grupo $2(++)$. Alta especificidad. Su diagnóstico en un niño o niña determina un alto índice de sospecha de abuso sexual, pero tienen otras vías de contagio que se deben investigar: VIH, hepatitis $B$, herpes simple 2, papilomavirus, Trichomonas vaginalis.

- Grupo $3(+)$. Baja especificidad. Su diagnóstico en un niño o niña no es indicativo de abuso sexual, pero obliga a investigar esta eventualidad: Gardnerella vaginalis, Mycoplasma hominis, Ureaplasma urealyticum, herpes simple 1, Candida albicans, Haemophylus ducreyi y Calymmatobacterium granulomatis.

En la Tabla 2 se esquematizan las posibles vías de contagio de los gérmenes capaces de causar ITS.

\section{Signos genitales relevantes}

Los hallazgos genitales relevantes para el diagnóstico no son lo más frecuente en el abuso sexual. Cuando existen, adquieren gran importancia por su elevada especificidad. Signos relevantes son aquellos compatibles con haber sido consecuencia de la penetración del pene o por otra forma de abuso empleada.

\section{Transplacentaria}

Infección intrauterina / infección ascendente

Perinatal

Por el canal de parto

CT, GC, TV, HSV, HPV, VHB, VHC, VIH

Por la lactancia

Contacto directo

Contacto no sexual / autoinoculación

Trasmisión por fómites

Drogas intravenosas y transfusión de sangre o derivados

Acto sexual consentido

Agresión sexual

VIH, VHB, VHC, sífilis, HPV

$\mathrm{CT}=$ Chlamydia trachomatis; $\mathrm{GC}=$ Neisseria gonorrhoeae; $\mathrm{VIH}=$ virus de inmunodeficiencia humana; $\mathrm{VHB}=$ hepatitis $\mathrm{B}$

$\mathrm{VHC}=$ hepatitis $\mathrm{C} ; \mathrm{HPV}=$ papiloma virus humano, HSV = herpes simplex virus, TV = Trichomonas vaginalis.
Tabla 2.

Vía de trasmisión de los agentes de ITS en población joven (Tomado de Thomas, et al., 2003). 
Así como es raro encontrar signos genitales de abuso sexual infantil, existen diferentes hallazgos genitales patológicos que no tienen que ver con esa entidad. Así como un examen genital negativo no descarta el abuso sexual, la mala interpretación médico-legal de los hallazgos genitales suelen dar lugar -o legitimardenuncias infundadas. Sobrevalorar la información del examen genital en las niñas es un error conceptual y metodológico que suele derivar de extrapolar a la infancia los criterios periciales válidos en las mujeres adultas ${ }^{2,7}$.

La utilidad del uso del colposcopio para la búsqueda de lesiones genitales en casos de atentados sexuales en mujeres postpuberales está bien demostrada ${ }^{11}$. Sin embargo, su uso en las niñas es mucho más discutido. No hay duda en cuanto al beneficio de permitir detectar y documentar lesiones genitales mínimas, pero si bien las imágenes fotográficas obtenidas por colposcopia en las niñas pueden ofrecer una mayor contundencia probatoria, e incluso posibilitar una segunda opinión sin un nuevo examen, la coincidencia en la interpretación de esas imágenes en niñas abusadas entre los expertos no es satisfactoria (entre el $58 \%$ y el $88 \%)^{12}$. Y en las niñas pequeñas, con maduración sexual Grado 1 y 2 de escala de Tanner, el nivel de desacuerdo entre los expertos es aún mayor ${ }^{13}$.

Tabla 3.

Tiempo de cicatrización de los desgarros himeneales según diversos autores.

\begin{tabular}{lc}
\hline Autor & Tiempo de cicatrización \\
\hline Hofmann & $2-4$ días \\
\hline Vibert & $2-12$ días \\
\hline Du Salle & $3-4$ días \\
\hline Gisbert Calabuig & $3-4$ días \\
\hline E. Martin & $3-4$ días \\
\hline Casas Sánchez & $3-4$ días \\
\hline Balthazard & $5-15$ días \\
\hline Rojas & 7 días \\
\hline Teke & 7 días \\
\hline Tedeschi & $7-10$ días \\
\hline Casper & $9-10$ días \\
\hline Kvitko & 10 días \\
\hline Lancís y Sánchez & 10 días \\
\hline Vargas Alvarado & 10 días \\
\hline Vanrell & 14 días \\
\hline de Pena & 15 días \\
\hline Tardieu & $15-20$ días \\
\hline
\end{tabular}

Cuando en las niñas pequeñas existe penetración vaginal se producen lesiones realmente graves, con grandes desgarros perineales o estallidos vaginales, que desencadenan cuadros agudos que requieren cirugías de emergencia, terapia intensiva y, frecuentemente, causan la muerte.

En las niñas mayores de 6 años, y cuanto más próxima está a la pubertad, los signos genitales de abuso son progresivamente similares a los observables en la mujer adulta.

Además de tomar en cuenta que no toda lesión genital es causada por abuso y que no todo abuso causa lesión genital, el perito debería tener presente que una gran parte de las lesiones genitales curan sin que persistan secuelas que permitan su posterior objetivación ${ }^{14,15}$.

Signos en el himen: Los desgarros himeneales son una evidencia de penetración, por lo que son un signo relevante y de una alta especificidad. Una buena exploración casi siempre permite diferenciarlos de las escotaduras congénitas, frecuentemente presentes en el borde libre del himen como variante anatómica 5,8,14-19. A cualquier edad, la integridad de la membrana himeneal (salvo los casos de los hímenes complacientes) descarta el coito vaginal, pero no las otras formas de abuso sexual sin penetración (las más frecuentes en la infancia y las únicas anatómicamente posibles en niñas pequeñas) ${ }^{2,4}$. Sin éxito alguno se ha intentado establecer una relación entre el diámetro del orificio himeneal y la posibilidad de haber sufrido abuso. Por el contrario, lo cierto es que ese diámetro varía en una misma niña por diversos factores, como la posición, la relajación alcanzada, la fuerza de tracción sobre los labios mayores aplicada por el perito, entre otras ${ }^{9,18}$. En consecuencia, es muy desaconsejable basarse en la medida del orifico himeneal como un elemento a favor, y mucho menos en contra, del diagnóstico de abuso sexual. Otro aspecto relevante desde el punto de vista pericial es la data de la lesión. El tiempo de cicatrización se sumamente variable ${ }^{19}$. La Tabla 3 demuestra la variabilidad en la experiencia de diferentes autores, lo que obliga al perito a una actitud de suma prudencia al datar el momento de producción.

Otras lesiones genitales traumáticas: Otro tipo de lesiones genitales traumáticas relevantes son los desgarros y las contusiones vulvares (introito, horquilla, clítoris, labios menores, meato uretral) causadas por maniobras de frotamiento, tocamiento o intento de penetración. Según la data de producción, pueden expresarse por sangrado activo, sufusiones hemorrágicas o lesiones cicatrizales. Se debe extremar la cautela y el sentido común en la interpretación de estas lesiones, sin olvidar que los traumatismos de 
vulva en la infancia (a partir del primer año de vida) tienen casi siempre una etiología accidental. En estos casos, la lesión resultante suele ser la equimosis, el hematoma o la herida contusa de los genitales externos, lo que no debería ser jamás confundido con una lesión originada en una agresión sexual2,3,7,9.

Vulvitis y vulvovaginitis: Se trata de una condición extremadamente común en las niñas (particularmente en las etapas de la primera infancia y la edad escolar), que la torna un motivo de consulta frecuente en pediatría. Sus causas son muy variadas: infección bacteriana, micosis, parasitosis, alergia, irritación, traumatismo, cuerpo extraño, higiene defectuosa (o excesiva) o autoestimulación de la propia niña. El flujo vaginal (excepto si es resultado de una infección por contagio venéreo) no debe considerarse un signo relevante de abuso sexual, aunque debe ser una alerta y justificar un planteo de posibilidad $2,7,18$.

Lesiones genitales en niños varones: Es una eventualidad bastante rara. Se han descrito varias lesiones de pene y escroto (edema, equimosis, mordeduras, cicatrices) causadas por abuso sexual. También puede presentarse exudado uretral u otras manifestaciones clínicas o de laboratorio de una ITS.

\section{Signos anales relevantes}

Para lo que atañe a los hallazgos anales en casos de sospecha de abuso sexual de niños y niñas caben algunas consideraciones similares a las realizadas respecto a las lesiones genitales. El abuso sexual suele ocurrir con indemnidad de la región anal y, paralelamente, existe una variedad de lesiones anales y/o rectales que no guardan relación alguna con abuso. Al igual que las lesiones genitales, pueden curar sin dejar secuelas.

Otro aspecto a tener bien presente es la posibilidad de variantes anatómicas del ano, sin ningún significado patológico que, sin embargo, pueden inducir a error. El llamado "ano entreabierto" (al flexionar los muslos sobre el tórax se puede visualizar el ano y el canal anal) es un hallazgo bastante común en niños normales no abusados. El "ano en embudo", que algunos textos clásicos consideraban signo de pederastia pasiva crónica, no tiene ningún valor -como dato aislado- para afirmar o descartar que haya existido actividad sexual por la vía anal. Sin embargo, tienen un valor para el diagnóstico cuando están asociadas a otros hallazgos como borramiento de los pliegues radiados, equimosis perianal, desgarro anal, disfunción esfinteriana o alegación del niño o la niña ${ }^{3}$.

Especial interés para el médico forense tiene el conocimiento de la morfología anal en el cadáver. Los hallazgos ano-rectales y perianales en el cadáver deben interpretarse con sumo cuidado. Esto es especialmente válido para los cadáveres de niños, niñas y adolescentes, en los que en el $74 \%$ de los casos el esfínter anal se presenta dilatado: en el $32 \%$ se visualiza el canal y la ampolla rectal, en el $32 \%$ se aprecia la línea pectínea y en el $10 \%$ sólo se ve el extremo más distal del canal anal ${ }^{20}$. Otros posibles hallazgos de autopsia no vinculados con abuso sexual son el ensuciamiento fecal, la congestión local y la hiperpigmentación del área perianal. En ocasiones, los cadáveres presentan livideces localizadas en el periné que pueden ser erróneamente interpretadas como sufusiones equimóticas.

Esfínter anal: La penetración anal aguda o crónica puede dar lugar a trastornos funcionales del esfínter anal. En los casos de penetración aguda suele acompañarse de lesiones traumáticas verificables a la inspección, tales como eritema, edema, equimosis o desgarro. Si el niño o la niña fue reiteradamente sodomizado puede encontrase un engrosamiento de la piel perianal. Cabe insistir en que la penetración anal, aún si es crónica, puede no dejar signos objetivables, dependiendo de la modalidad en que se perpetra la agresión. La penetración ano-rectal podrá causar o no lesiones traumáticas en función de cómo se combinen las siguientes:

- Grado de la desproporción anatómica.

- Grado de brusquedad de la penetración.

- Existencia o no de maniobras previas de dilatación.

- Uso o no de lubricación.

- Pasividad o resistencia de la víctima.

Cuando más pequeña es la víctima mayor es el daño, que puede llegar a causar el estallido rectal y la muerte, por hemorragia incoercible o peritonitis. Cuando la penetración es apenas parcial, o tiene lugar en niñas y niños mayores o adolescentes, lo habitual es que no cause lesiones traumáticas objetivables"2, La incontinencia fecal y el "ensuciamiento" sin lesión anatómica traumática asociada no suele ser resultado de la penetración rectal peneana. De estar ante una situación abusiva, se explicaría más como respuesta de la esfera psicológica que por un mecanismo traumatismo local.

Desgarro anal: La lesión más típica de la penetración anal es el Ilamado desgarro de Wilson Johnston, de forma triangular a vértice luminal y base en el margen anal a nivel del rafe medio (a la hora 6 , si se examina a la víctima en posición genu-pectoral) ${ }^{17}$. Sin perjuicio de esto, el desgarro puede tener otras 
topografías y ser múltiple ${ }^{14}$. Cuando el desgarro es reciente se acompaña siempre de sangrado y, algunas veces, de la parálisis dolorosa del esfínter. Normalmente curan a los cinco días, plazo que en los casos graves se extiende a dos semanas ${ }^{8}$.

Otras lesiones anales: La fisura anal es una entidad de alta prevalencia en la edad pediátrica. Se la asocia con constipación, diarrea y a veces es de causa desconocida. Por ello, como hallazgo aislado, no debería motivar sospechas de abuso sexual. La inflamación o infección del ano y el recto (excepto cuando son causadas por una ITS) no son datos suficientes para diagnosticar un abuso sexual. Tampoco el prolapso rectal debe orientar al diagnóstico de abuso sexual.

\section{Alegación del niño o la niña}

La alegación de abuso sexual por una niña o niño es un hecho muy poco frecuente, y casi excepcional en los casos de abuso intradomiciliario ${ }^{2,3}$. Este hecho no sólo se explica por la existencia de vergüenza, miedo y amenazas del abusador, sino por la presencia de sentimientos de culpa en la víctima y falta de atención y comprensión a sus pedidos de ayuda por parte de las personas a su cargo.

Si bien la alegación constituye un elemento anamnésico, y por ello imposible de objetivar, debería valorarse como un elemento de muy alta especificidad, en tanto resulte de un relato espontáneo.

Esta alegación puede no ser realmente espontánea y, por ello, perder su carácter de elemento diagnóstico de alta especificidad. Por ello, la entrevista a un niño posiblemente abusado sexualmente constituye un insumo pericial de inestimable valor, que debe ser realizado por personal entrenado y de acuerdo a las

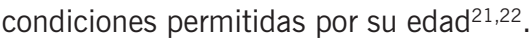

Existen varias posibles causas de una alegación no es espontánea $2,9,21,22$ :

- Reiteración del interrogatorio. Una de las causas más comunes de ello es la mala práctica de prodigar los interrogatorios a niñas y niños en el sistema de salud. Suele verse ante una sospecha -fundada o no- que se interroga al niño/a y, ante su negativa, se reitera múltiples veces el interrogatorio, hasta que en un momento cambia la versión.

- Mala técnica del interrogatorio. La anamnesis al niño debe procurar preservar la espontaneidad del relato, por su valor clínico, pericial y probatorio. Cuando el interrogador induce las respuestas a través de la pregunta que formula o del lenguaje no verbal (sea través de gestos o exteriorización de sus emociones), el relato se contamina de vocablos e ideaciones adultas y pierde valor todo su valor diagnóstico pericial.

- Relatos inducidos. La alegación del niño puede haber sido inducida por adultos y orientarse a obtener un beneficio secundario para éstos. Los relatos falsos son mucho más raros y se pueden deber al interés de un beneficio secundario del niño/a o a una patología psiquiátrica.

La mayoría de las falsas alegaciones tiene su origen en las personas adultas. Dentro de las causas de falsas alegaciones se han destacado las siguientes ${ }^{22}$ :

- Por influencia de una figura adulta con autoridad. El caso más frecuente es el de uno de los padres que "adoctrina" a la niña o el niño cuando de la falsa alegación puede obtener un beneficio secundario (v.g.: juicio de tenencia, venganza), lo que se ha denominado síndrome de alienación parental ${ }^{23}$. En otras ocasiones se trata de patologías delirantes o trastornos facticios (síndrome de Munchausen por poder).

- Por iatrogenia, cuando el entrevistador, desde su lugar de autoridad (judicial, policial o sanitaria), no se muestra neutro e influye en el niño en el sentido de la falsa alegación. El niño busca complacer a la autoridad; en especial, cuando se le reiteran las mismas preguntas puede cambiar la respuesta para satisfacer al entrevistador.

Resulta compleja la posibilidad de entrevistar a niñas y niños muy pequeños. Al respecto, la mayoría de los expertos desaconseja entrevistar a los menores de tres años ${ }^{9}$. Ello no obsta que algunas pautas admitan la posibilidad de valorar a las niñas y niños muy pequeños -aún los lactantes- cuando se emplean técnicas muy especializadas y éstas son aplicadas por técnicos competentes ${ }^{21,24}$.

Algunos protocolos recomiendan que en la entrevista sólo estén presentes el niño y el examinador, como forma de lograr un relato menos influenciable por el adulto a cargo ${ }^{9,21}$. Ésta no es una norma de valor absoluto y, si la entrevista está realizada por un técnico experimentado, la presencia del adulto no es un obstáculo para obtener elementos de valor pericial ${ }^{2}$.

Algunas técnicas de apoyo durante la entrevista, como los dibujos o las muñecas, pueden ser de buena utilidad, a condición de ser aplicadas e interpretadas por técnicos formados y experimentados ${ }^{9,21}$.

A efectos probatorios y de evitar la duplicación de interrogatorios y la victimización secundaria, es 
recomendable el uso de la cámara Gessell, así como la audio y la videograbación ${ }^{2,21}$.

Otras técnicas, como las que emplean muñecos sexuados, son muy controvertidas, por lo que debe desaconsejarse su empleo con finalidad diagnóstica (aunque sí puedan tener una utilidad terapéutica) ${ }^{25-28}$.

En conclusión, la alegación del niño o la niña, cuando se acompaña de un informe psicológico de veracidad, constituye un indicador de alta especificidad, tan fiable como los signos físicos considerados característicos ${ }^{5,6}$.

\section{Elementos de baja especificidad diagnóstica}

Las formas y las manifestaciones del abuso sexual en niñas y niños son extremadamente variadas. Pese a ello, casi nunca faltan ciertas manifestaciones no explicables como una consecuencia física sino psicológica del abuso (aunque sintomáticamente puedan tener expresión orgánica y/o psicológica) que dan cuenta de la existencia de algún factor estresor. Estas manifestaciones son generalmente inespecíficas, representando una respuesta común a diferentes tipos de estresores. Por ello, se trata de manifestaciones muy sensibles pero con una muy pobre especificidad diagnóstica ${ }^{2,3,29}$.

Estas manifestaciones de alerta, aunque inespecíficas, suelen ser un motivo de consulta pediátrica o psicológica, o son detectadas porque llaman la atención del maestro, aunque no siempre determinen inicialmente la sospecha de abuso sexual ${ }^{2,7}$.

\section{Síntomas y manifestaciones de la esfera orgánica}

El daño ocasionado por el abuso sexual suele exteriorizarse como un signo o síntoma de carácter físico. Ni su aparición ni su persistencia pueden inicialmente ser explicadas por el pediatra o la familia.

Entre las múltiples manifestaciones posibles, por su frecuencia, destacamos las siguientes: dolor abdominal recurrente, episodios de cefalea recurrentes, enuresis secundaria y encopresis secundaria. La simulación de una patología de base orgánica puede determinar que el niño sea sometido a estudios invasivos para descartar una causa estructural de los síntomas.

Obviamente, todas éstas son situaciones extremadamente frecuentes en pediatría, de cuyo total sólo un mínimo porcentaje corresponde a síntomas desencadenados por el abuso sexual, ya que puede estar ocasionado por una gran variedad de estresores. Sin embargo, en el contexto de una sospecha de abuso sexual, y a falta de otra causa de estrés psíquico conocido, adquieren considerable significado ${ }^{2,3}$.
Síntomas y manifestaciones de la esfera psicológica

Están presentes en casi todas las víctimas de abuso sexual, aunque por su carácter altamente inespecífico no contribuyen demasiado a alcanzar un diagnóstico precoz. En todo caso, cuando se conoce su valor como indicadores inespecíficos, son elementos que determinan un aumento del índice de sospecha, estimulan la investigación y, en última instancia, contribuyen al diagnóstico de abuso sexual ${ }^{2,3,9,21}$.

Erotización inadecuada para la edad: Dentro de la inespecificidad diagnóstica de los síntomas psicológicos y las alteraciones del desarrollo, se considera que una conducta inadecuadamente sexualizada para la edad es la manifestación más significativa dentro de esta categoría ${ }^{2,22}$. Si bien no es muy frecuente, su presentación fundamenta una alta sospecha ${ }^{3}$.

La determinación de qué es o no es adecuado para la edad depende de una valoración experta, generalmente a cargo de un psicólogo y psiquiatra pediatra. Estas conductas pueden incluir besos con contacto de lengua, tocamiento de las mamas y los genitales, masturbación compulsiva y movimientos rítmicos de la pelvis ${ }^{3}$. Se han señalado los siguientes criterios para considerar que la conducta sexualizada es problemática $^{3,30}$ :

- Se presenta con mucha frecuencia o en una etapa mucho más a lo esperado.

- Interfiere con el desarrollo del niño o la niña, como cuando se relaciona en la escuela a través de estos comportamientos.

- Se acompaña del uso de la intimidación o la fuerza para hacer participar a otros coetáneos.

- Se asocia con otros trastornos psicológicos.

- Se repite a escondidas de sus padres o cuidadores.

Otras manifestaciones: Pueden ser sumamente variadas y tener diversos grados de gravedad. Una de las manifestaciones más comunes es la detección de inflexiones en el rendimiento escolar sin explicación aparente. A veces puede llevar a retraso y al fracaso escolar. En los niños más pequeños, el equivalente es el retraso en el desarrollo con la regresión en las conductas adquiridas.

A veces los cambios en la conducta asumen la forma llamada pseudomadurez, por la que las niñas asumen roles y actitudes correspondiente a una edad superior. La pseudomadurez suele verse en casos de abuso sexual incestuoso, en el que la niña inconscientemente 
es llevada a ocupar el rol materno, muchas veces física o afectivamente ausente.

Los trastornos del humor, con síntomas de depresión y ansiedad, son muy frecuentes. Puede haber autoagresividad con episodios suicidas o parasuicidas, pero también es muy frecuente la heretoagresividad y la irritabilidad.

Pueden presentarse como niños y niñas con una muy baja autoestima.

Otras manifestaciones, como fobias, pesadillas y terrores nocturnos, no deberían considerase per se, en forma aislada, como indicadores de sospecha de una situación de abuso sexual, habida cuenta de que su presencia es habitual y esperable a determinadas edades.

\section{Conclusión}

En la generalidad de los casos, la peritación del abuso sexual de niños y niñas entraña grandes dificultades.
Prácticamente no existen indicadores de certeza (manifestaciones patognomónicas) o de elevada especificidad, y los que existen se presentan en muy pocos casos.

Por el contrario, casi todos los casos presentan indicadores de sospecha (manifestaciones inespecíficas), que indican la acción de estresores sobre la víctima, una de las cuales puede ser el abuso sexual. El diagnóstico supondrá descartar otras causas de estrés que expliquen los síntomas.

La aplicación a las niñas y niños de los principios y criterios médico-legales de las agresiones sexuales a personas adultas es causa de graves errores periciales. En especial, centrar la investigación pericial en los hallazgos genitales (positivos o negativos) es un grave error metodológico que lleva a pasar por alto la inmensa mayoría de los casos, a la vez que a incurrir en diagnósticos erróneos, todo lo que genera graves daños a las niñas, los niños y sus familias.

La peritación médico-legal del abuso sexual reconoce diez principios de carácter general, que se resumen en la Tabla 4.

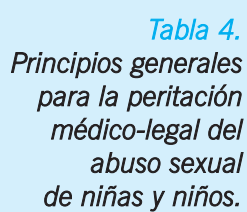

Tabla 4.

Principios generales para la peritación de niñas y niños.
No extrapolar en forma mecánica los criterios válidos para la peritación de agresiones sexuales en personas adultas.

En la mayoría de los casos el abuso sexual de niñas y niños no produce estigmas físicos.

Los signos y síntomas del abuso sexual casi siempre son de carácter inespecífico.

Los hallazgos patognomónicos de abuso sexual son excepcionales.

Las infecciones de trasmisión sexual no necesariamente se contraen por contagio venéreo.

La producción de lesiones genitales en niñas y niños pequeños sexualmente abusados no es la regla.

La producción de lesiones anales en niñas y niños pequeños sexualmente abusados no es la regla.

Cuando cumple con los criterios de validez, la entrevista a la niña o el niño es una etapa clave de la peritación médico-legal.

Está contraindicada la reiteración del interrogatorio y el examen físico.

El diagnóstico de abuso sexual de niñas y niños es uno de los desafíos más difíciles de la medicina legal. 


\section{Bibliografía}

1. World Health Organization. Report of the Consultation on Child Abuse and Neglect Prevention, 29-31 March, Geneva. Ginebra: World Health Organization; 1999. Document WHO/HSC/PVI/99.1.

2. Rodríguez Almada H. Maltrato y abuso sexual de niños. Una revisión crítica. Granada: Comares; 2006.

3. World Health Organization. Guidelines for medicolegal care for victims of sexual violence. Ginebra: World Health Organization; 2003.

4. Suárez Solá ML, González Delgado FJ. Estadísticas y trascendencia de la violencia sexual en menores. Cuad Med Forense 2003;32:49-62.

5. Castelló A, Francès F, Verdú F. Investigación médico forense de los delitos contra la libertad e indemnidad sexuales. Cuad Med Forense 2009;15(55):17-35.

6. Gil Arrones J, Ostos Serna R, Largo Blanco E, Acosta Gordillo L, Caballero Trigo MA. Valoración médica de la sospecha de abuso sexual en personas menores de edad. A propósito del estudio de tres casos. Cuad Med Forense 2006;12(43-44):57-74.

7. Rodríguez Almada H. Abuso sexual de niñas y niños. Montevideo: Bibliomed 2007; 127-43.

8. Gisbert Grifo M, Gisbert Calabuig JA. Delitos contra la libertad e indemnidad sexuales. En: Gisbert Calabuig JA. Medicina legal y toxicología. $6^{a}$ ed. Barcelona: Masson 2004;579-601.

9. American Academy of Pediatrics Committee on Child Abuse and Neglect. Guidelines for the Evaluation of Sexual Abuse of Children: Subject Review (RE9819). Pediatrics 1999;103:186-91.

10. Thomas A, Forster G, Robinson A, Rogstad K. National guideline for the management of suspected sexually transmitted infections in children and young people. Arch Dis Child 2003;88:303-11.

11. Mancino P, Parlavecchio E, Melluso J, Monti M, Russo P. Introducing colposcopy and vulvovaginoscopy as routine examinations for victims of sexual assault. Clin Exp Obstet Gynecol 2003;30:40-2.

12. Muram D, Arheart KL, Jennings SG. Diagnostic accuracy of colposcopic photographs in child sexual abuse evaluations. J Pediatr Adolesc Gynecol 1999;12:58-61.

13. Sinal SH, Lawless MR, Rainey DY, Everett VD, Runyan DK, Frothingham T, Herman-Giddens M, St Claire K. Clinician agreement on physical findings in child sexual abuse cases. Arch Pediatr Adolesc Med 1997;151:497-501.
14. Berkoff MC, Zolotor AJ, Makoroff KL, Thackeray JD, Shapiro RA, Runyan DK. Has this prepubertal girl been sexually abused? JAMA 2008;300:2779-92.

15. Heppenstall-Heger A, McConnell G, Ticson L, Guerra L, Lister J, Zaragoza T. Healing patterns in anogenital injuries: a longitudinal study of injuries associated with sexual abuse, accidental injuries, or genital surgery in the preadolescent child. Pediatrics 2003;112:829-37.

16. Kvitko LA. El himen. Estudio medicolegal. Buenos Aires: Ed. La Rocca 2005

17. Kvitko LA. La violación. Peritación medicolegal en las presuntas víctimas del delito. $2^{a}$ edición. México: Trillas 1995.

18. Heger AH, Ticson L, Guerra L, Lister J, Zaragoza T, McConnell G, Morahan M. Appearance of the genitalia in girls selected for nonabuse: review of hymeneal morphology and nonspecific findings. J Pediatr Adolesc Gynecol 2002;15:27-35.

19. Vanrell J. Sexologia Forense. Sao Paulo: Mizuno 2008.

20. McCann J, Reay D, Siebert J, Stephens B, Wirtz S. Postmortem Perianal Findings in Children. Am J Forensic Med Pathol 1996;17:289-98.

21. Kellogg N. Committee on Chlid Abuse and Neglect. The Evaluation of Sexual Abuse in Children. Pediatrics 2005;116:506-12.

22. Lipian MS, Mills MJ, Brantman A. Assessing the verity of children's allegations of abuse: A psychiatric overview. Int J Law Psychiatry 2004;27:249-63.

23. Segura C, Gil MJ, Sepúlveda MA. El síndrome de alienación parental: una forma de maltrato infantil. Cuad Med Forense 2006;12(43-44):117-28.

24. American Academy of Child and Adolescent Psychiatry Practice Parameters for the Forensic Evaluation of Children and Adolescent who may have been Physically or Sexually Abused. J Am Acad Child Adolesc Psychiatry 1997;36 (10 Supp):375-563.

25. Britton $\mathrm{HL}$, O'Keefe MA Use of nonanatomical dolls in the sexual abuse interview. Child Abuse \& Neglect 1991;15:567-73.

26. Everson MD, Boat BW Sexualized doll play among young children: implications for the use of anatomical dolls in sexual abuse evaluations. J Am Acad Child Adolesc Psychiatry 1990;29:736-42.

27. Everson MD, Boat BW. Putting the anatomical dolls controversy in perspective: An examination of the major uses and criticisms of the dolls in child sexual abuse evaluations. Child Abuse \& Neglect 1994;18:113-30. 
28. Koocher GP, Goodman GS, White CS, Friedrich WN, Sivan AB, Reynolds CR. Psychological science and the use of anatomically detailed dolls in child sexual-abuse assessments. Psychol Bull 1995;118:199-222.

29. Waterman J, Lusk R Psychological testing in evaluation of child sexual abuse. Child Abuse \& Neg/ect 1993;17:145-59.
30. Kendall-Tackett KA, Williams LM, Finkelhor D. Impact of sexual abuse on children. A review and synthesis of recent empirical studies. Psychological Bulletin 1992;113:164-80. 